\title{
The effects of programmed therapeutic exercises on fall risk factors in the elderly
}

\author{
Bakir Katana1*, Samir Bojičić ${ }^{1}$, Muris Pecar ${ }^{1}$, Eldad Kaljić ${ }^{1}$, Namik Trtak ${ }^{1}$, Emina Smajić ${ }^{2}$
}

'Department of Physiotherapy, Faculty of Health Sciences, University of Sarajevo, Sarajevo, Bosnia and Herzegovina, 2Department of Cytology, Poliklinika Sunce Agram, Sarajevo, Bosnia and Herzegovina

\begin{abstract}
Introduction: Identification of the risk factors that can be modified is an essential aspect in the development of the effective strategy for therapeutic intervention with the purpose to improve mobility and injury prevention and post-fall consequences. This research aimed to analyze the impact of programmed therapeutic exercises on the fall risk factors in the elderly.
\end{abstract}

Methods: We included 260 patients older than 65 years and assigned them randomly into three groups: Group A: 65 patients subjected to therapeutic exercises for moderate-intensity muscle strengthening with Theraband stretch straps (corresponding to 11-14 on the Borg rating of perceived exertion scale), Group B: 65 patients subjected to therapeutic anti-gravity exercises, and control group: 130 patients not participating in programmed therapeutic exercises. The presence of fall risk factors was assessed in all three groups with standardized Fast Evaluation of Mobility, Balance, and Fear test before the initiation of therapy, after 3 and after 6 months of treatment.

Results: At the end of the study, the subjects of the Group A had significantly fewer limitations in performing basic life activities at home compared to the patients of the control and Group B, $p=0.037$. The control group subjects were statistically significantly more likely to complain of vertigo than subjects of the experimental groups, $p=0.021$. The subjects of the experimental groups had more than two falls than the control group subjects, $p=0.003$ statistically. In the control group, the number of fractures after the fall at the end of the study increased significantly, statistically higher than in the subjects of the experimental groups, $p=0.037$.

Conclusion: Programmed therapeutic exercise significantly reduces the risk of falling factors, and significant effects have been achieved among subjects who have exercised with elastic strips.

Key words: The elderly; fall risk factors; therapeutic exercises

\section{INTRODUCTION}

Aging is a physiological process. The number of people over 60 years old in the world is growing faster than any

\footnotetext{
*Corresponding author: Bakir Katana, Department of Physiotherapy, Faculty of Health Sciences, University of Sarajevo, Bolnička 25, 71000 Sarajevo, Bosnia and Herzegovina. E-mail: bakirkatana@gmail.com
}

Submitted: 3 October 2018 / Accepted: 11 November 2018 other age group (1). It was estimated at 688 million in 2006 and will increase to 2 billion by 2050. Falls increase exponentially with age-related biological change. Hence, an increase in the number of people over 80 years of age will cause a significant increase in falls and fall-related injuries at high speed (2).

Falls is the sixth leading cause of injury-related deaths in older than 65 , and $70 \%$ of interventions in emergency medical services are associated with a fall 
in older people than 75 (3). Falls account for $40 \%$ of all injury-related deaths. Rates vary depending on the country and the observed population. The mortality rate caused by falls in people aged 65 and over increases and the mortality rate for the same age group in Canada is 9.4/10,000 inhabitants. The rates of fatal fall exponentially increase with age for both the sexes, and most of them are aged 85 and over (4). Falls are the result of complex interaction of damaged functions and environmental elements. Poor mobility of older adults can be one of the causes of falls. The main reasons for immobility are weakness, stiffness, pain, imbalance, and psychological problems (3).

The economic impact of falls is crucial for the family, community, and society. Health-care impacts and falls in older age are increasing significantly throughout the world (5). Furthermore, the cumulative effect of falls and resulting injuries among older people in most countries have the potential to achieve epidemic proportions, which would require a disproportionate amount of health-care resources (6). Injuries caused by falls are the most expensive category of injuries in the elderly. The elderly who suffered a fall had higher costs of treatment than the elderly who had injuries which were not caused by a fall (7).

As noted above, falls are a common health problem in the elderly, which can lead to injury, hospitalization, institutionalization, and even mortality. Therefore, it is essential to understand the risk of fall factors to identify the objectives for intervention and prevention (8). The risk of fall increases with age and is more common in women than in men. 1-3 falls are registered annually, which makes 25-35\% of all persons over 56 years of age and older.

Two to three people who have fallen will have a fall within 6 months again, and one in four who have had a hip fracture will have a fatal outcome after 6 months of injury (3).

Identifying the risk of factors that can be modified is a critical aspect in developing an effective therapeutic intervention strategy to improve mobility, injury prevention, and post-fall consequences (9). Tinetti and Speechley (8) examined $>60$ studies on potential fall risk factors and identified $>25$ risk factors. By reviewing available scientific resources, they defined with strong evidence certain factors that are associated with the fall risk. These risk factors include high age, movement restrictions, history of falls, impaired physical mobility, altered pacing, vision problems, reduced sensitivity, decreased muscle strength, poor reaction time, fear of falling, and more medical factors ranging from cognitive disorders to a range of chronic diseases (8). Other risk factors include the use of aids, the use of certain drugs, the use of multiple medications, the use of alcohol, and risky behavior (10).

Factors that affect the incidence of falls in the elderly may be intrinsic or extrinsic (11). Intrinsic and extrinsic factors can be further divided into four categories of risk factors that reflect a multitude of health determinants that directly or indirectly affect good health: Biological risk factors, behavioral risk factors, risk factors from the environment, and socioeconomic risk factors (12).

Therapeutic exercise is used to prevent injuries, improve function, reduce risk, optimize overall health, and then improve physical health. Particular emphasis has been laid on the need for regular exercises (13). For people older than 65, therapeutic muscle strength enhancement exercises are recommended for reducing the risk of falls and fractures and for improving the ability to live independently (14).

This study aims to analyze the impact of programmed therapeutic exercises on the fall risk factors in the elderly.

\section{METHODS}

\section{Patients}

The study was designed as an interventive (manipulative), open, randomized, prospective analytical research conducted in the "Center for Healthy Aging" Sarajevo in the period from September 2014 to March 2015.

We included 260 participants who were randomly assigned to three groups. Group A included 65 patients subjected to therapeutic exercises for moderate-intensity muscle strengthening with Theraband stretch straps (which should correspond to $11-14$ on the Borg rating of perceived exertion scale). Group B included patients subjected to 
therapeutic anti-gravity exercises. The control group included 130 patients aged over 65 who did not participate in programmed therapeutic activities but were subjected to assessment of the risk of falls.

\section{Therapeutic exercises of Group A}

In the experimental Group $A$, the program of therapeutic exercises consisted of therapeutic exercises of moderate intensity with Theraband tape for $40 \mathrm{~min}$. To strengthen the muscles of the trunk and upper and lower extremities, each session consisted of a 5-min warm-up therapeutic exercise and 30-min therapy exercises with a Theraband tape, for which the subjects were instructed to do the exercises with moderate intensity.

The subjects were instructed to gradually (every 2-4 weeks) increase the band resistance by switching to another band color (from the weakest to the strongest: Yellow, red, green, blue, black, silver, and gold) or by wrapping the bands around their hands several times to shorten them and thus increase elastic band resistance. The subjects increased the band resistance when they were able to perform 20 repetitions of a particular movement with some effort. After the exercise, the therapeutic relaxation training lasted for $5 \mathrm{~min}$. Therapeutic exercises were performed 3 times a week, $40 \mathrm{~min} /$ day.

\section{Therapeutic exercises of Group B}

In the examined subgroup $B$, therapeutic anti-gravity exercises, i.e., non-resistance therapeutic exercises, were represented as therapeutic breathing exercises, therapeutic balance exercises, and therapeutic coordination exercises, therapeutic exercises to increase the mobility of the upper and lower extremities, therapeutic exercises to increase flexibility of lumbar and cervical spine, and therapeutic exercises for toning the upper and lower extremity muscles. Therapeutic exercises were performed 3 times a week for $40 \mathrm{~min} /$ day. The programmed therapeutic exercise for both groups continually lasted for 6 months (15).

\section{Instruments for assessing the fall risk}

The Fast Evaluation of Mobility, Balance, and Fear (FEMBAF) assessment was used as a measuring tool. The following components are measured: (1) The number of risk factors, (2) execution of assigned tasks, and (3) presence of subjective complaints on fear, pain, mobility difficulties, and lack of strength while performing the tasks (16). The number of risk factors was evaluated based on 22 elements, which are scored according to the dichotomous response model of "yes-no answer." All affirmative conditions are added together, and this sum enables a relative index number of risk factors that can affect the fall. The risk factor assessment is based on observations, statements of patients, and information from medical history. The fall risk assessment for this research has been conducted 3 times: Before the initiation of the therapy, after 3 months, and after completion of the therapy at 6 months.

\section{Statistical analysis}

SPSS for Windows (version 20.0, SPSS Inc., Chicago, Illinois, USA) and Microsoft Excel (version 10. Microsoft Corporation, Redmond, WA, USA) were used for statistical analysis of the obtained data. Distribution of data was analyzed using the Kolmogorov-Smirnov or Shapiro-Wilk test. For the demonstration of the mean value and the measures of dispersion, we used the median and interquartile range but for their comparison non-parametric test (Mann-Whitney U-test). Nominal and ordinal variables in the study were analyzed by Chi-square test, and with the missing of expected frequency, we used Fisher's exact test. Pearson's Chi-square test was used to distinguish the divisions of nominal and ordinal data and Fisher's exact test and Yates correction in the case of missing frequencies while comparing variables. Relationships between variables were analyzed by Spearman's rank correlation test.

\section{RESULTS}

In the control group, there were 55\% male and 45\% female subjects. In Group A, there were 12.3\% male and $87.8 \%$ female subjects, while in Group B, the percentage was $6.1 \%$ male and $93.3 \%$ female. The mean age of the control group subjects was 73.25 \pm 6.69 years of age (65-87) while, in Group A, was $71.28 \pm 5.21$ years of age (65-84) and $72.56 \pm$ 5.15 years $(65-85)$ in Group B.

In this research, there was no statistically significant difference in the needs for assistance in two or more 
basic daily activities, $p=0.352$. It was neither necessary for someone's assistance in performing two or more basic instrumental activities of daily life, $p=0.411$.

The subjects of the control group had statistically significantly fewer fractures compared to respondents of the experimental groups, $p=0.048$ (Table 1).

Control group subjects had statistically significantly fewer sequels compared to subjects of the examined groups, $p=0.037$ (Table 2).

There was no statistically significant difference in the use of walking aids in relation to the experimental group throughout all three surveys, $p=0.579$.

At the end of the study, the subjects of the experimental Group A had significantly fewer limitations in performing basic life activities at home compared to the subjects of the control and Group B, $p=0.037$ (Table 3).

Most of the subjects from all three groups did not find themselves as an anxious and statistically significant difference was not found, $p=0.789$.

The subjects of the control group complained about vertigo more significantly than the subjects of the experimental groups, $p=0.021$ (Table 4). The subjects of the control group statistically complained less on the balance disorder comparing to the subjects of the experimental groups, $p=0.037$ (Table 5). The subjects of the experimental Group A had more frequent postural hypotension than those of the experimental Group B and the whole control group, $p=0.011$ (Table 6).

There were no statistically significant differences in whether the subjects had a fall once or twice in the current year compared to the experimental group, $p=0.689$. Unlike the control group subjects, $p=0.003$ (Table 7), the subjects of the experimental groups had $>2$ falls statistically in the current year.

At the end of the study, the control group subjects demonstrated the need for medical assistance after the fall and that need was significantly more highlighted than in the subjects of the experimental groups, $p=0.043$ (Table 8 ). In the control group, the number of fractures after the fall increased significantly at the end of the study, significantly more than in the subjects of the experimental groups, $p=0.037$ (Table 9).
TABLE 1. Previous fractures or deficiencies on hips, knees, ankle joints, or feet

\begin{tabular}{cccc}
\hline Groups & $\begin{array}{c}\text { First survey } \\
n(\%)\end{array}$ & $\begin{array}{c}\text { Second survey } \\
n(\%)\end{array}$ & $\begin{array}{c}\text { Third survey } \\
n(\%)\end{array}$ \\
\hline $\begin{array}{c}\text { Control } \\
\text { Yes }\end{array}$ & $98(75.0)$ & $98(75.0)$ & $89(68.3)$ \\
No & $33(25.0)$ & $33(25.0)$ & $41(31.7)$ \\
Group A & & & \\
Yes & $49(75.0)$ & $48(73.3)$ & $48(73.3)$ \\
No & $16(25.0)$ & $17(26.7)$ & $17(26.7)$ \\
Group B & & & \\
Yes & $47(71.7)$ & $48(73.3)$ & $48(73.3)$ \\
No & $18(28.3)$ & $17(26.7)$ & $17(26.7)$ \\
\hline$X=5.111 ;$ & & &
\end{tabular}

$X=5.111 ; p=0.048$

TABLE 2. The presence of visible sequels on on hips, knees, ankle joints, or feet

\begin{tabular}{cccc}
\hline Groups & $\begin{array}{c}\text { First survey } \\
n(\%)\end{array}$ & $\begin{array}{c}\text { Second survey } \\
n(\%)\end{array}$ & $\begin{array}{c}\text { Third survey } \\
n(\%)\end{array}$ \\
\hline $\begin{array}{c}\text { Control } \\
\text { Yes }\end{array}$ & $77(59.2)$ & $77(59.2)$ & $64(49.2)$ \\
No & $53(40.8)$ & $53(40.8)$ & $66(50.8)$ \\
Group A & & & \\
Yes & $47(71.7)$ & $47(71.7)$ & $43(66.7)$ \\
No & $18(28.3)$ & $18(28.3)$ & $22(33.3)$ \\
Group B & & & \\
Yes & $47(71.7)$ & $47(71.7)$ & $46(70.0)$ \\
No & $18(28.3)$ & $18(28.3)$ & $20(30.0)$ \\
\hline$X=6.782 ;$ & 0.037 & &
\end{tabular}

$X=6.782 ; p=0.037$

TABLE 3: LIMITATIONS TO DAILY LIVING TASKS

\begin{tabular}{cccc}
\hline Group & $\begin{array}{c}\text { First survey } \\
n(\%)\end{array}$ & $\begin{array}{c}\text { Second survey } \\
n(\%)\end{array}$ & $\begin{array}{c}\text { Third survey } \\
n(\%)\end{array}$ \\
\hline $\begin{array}{c}\text { Control } \\
\text { Yes }\end{array}$ & $13(10.0)$ & $16(12.5)$ & $21(15.8)$ \\
No & $117(90.0)$ & $114(87.5)$ & $109(84.2)$ \\
Group A & & & \\
Yes & $5(8.3)$ & $4(6.7)$ & $3(5.0)$ \\
No & $60(91.7)$ & $61(93.3)$ & $62(95.0)$ \\
Group B & & & \\
Yes & $3(5.0)$ & $8(11.7)$ & $8(11.7)$ \\
No & $62(95.0)$ & $57(88.3)$ & $57(88.3)$ \\
\hline X=6.729; $p=0.037$ & &
\end{tabular}

The subjects of the experimental Group A generally had a greater fear than those of the control group and Group B, $p=0.047$. 
TABLE 4. The incidence of vertigo

\begin{tabular}{lccc}
\hline Group & $\begin{array}{c}\text { First survey } \\
n(\%)\end{array}$ & $\begin{array}{c}\text { Second survey } \\
n(\%)\end{array}$ & $\begin{array}{c}\text { Third survey } \\
n(\%)\end{array}$ \\
\hline $\begin{array}{c}\text { Control } \\
\text { Yes }\end{array}$ & $75(57.5)$ & $72(55.0)$ & $69(53.3)$ \\
No & $55(42.5)$ & $59(45.0)$ & $61(46.7)$ \\
Group A & & & \\
Yes & $37(56.7)$ & $38(58.3)$ & $38(58.3)$ \\
No & $28(43.3)$ & $27(41.7)$ & $27(41.7)$ \\
Group B & & & \\
Yes & $43(66.7)$ & $37(56.7)$ & $31(48.3)$ \\
No & $22(33.3)$ & $28(43.3)$ & $34(51.7)$ \\
\hline$X=8.963 ;$ & 0.021 & &
\end{tabular}

$\mathrm{X}=8.963 ; p=0.021$

TABLE 5. Complaints for balance loss

\begin{tabular}{lccc}
\hline Group & $\begin{array}{c}\text { First survey } \\
n(\%)\end{array}$ & $\begin{array}{c}\text { Second survey } \\
n(\%)\end{array}$ & $\begin{array}{c}\text { Third survey } \\
n(\%)\end{array}$ \\
\hline $\begin{array}{c}\text { Control } \\
\text { Yes }\end{array}$ & $72(55.0)$ & $64(49.2)$ & $64(49.2)$ \\
No & $59(45.0)$ & $66(50.8)$ & $66(50.8)$ \\
$\begin{array}{c}\text { Group A } \\
\text { Yes }\end{array}$ & $33(50.0)$ & $37(56.7)$ & $37(56.7)$ \\
No & $33(50.0)$ & $28(43.3)$ & $28(43.3)$ \\
$\begin{array}{c}\text { Group B } \\
\text { Yes }\end{array}$ & $39(60.0)$ & $37(56.7)$ & $30(46.7$ \\
No & $26(40.0)$ & $28(43.3)$ & $35(53.3)$ \\
\hline X & & &
\end{tabular}

$\mathrm{X}=8.382 ; p=0.037$

TABLE 6. Postural hypotension complaints

\begin{tabular}{lccc}
\hline Group & $\begin{array}{c}\text { First survey } \\
n(\%)\end{array}$ & $\begin{array}{c}\text { Second survey } \\
n(\%)\end{array}$ & $\begin{array}{c}\text { Third survey } \\
n(\%)\end{array}$ \\
\hline $\begin{array}{l}\text { Control } \\
\text { Yes }\end{array}$ & $55(42.5)$ & $55(42.5)$ & $48(36.7)$ \\
No & $75(57.5)$ & $75(57.5)$ & $82(63.3)$ \\
$\begin{array}{l}\text { Group A } \\
\text { Yes }\end{array}$ & $26(40.0)$ & $26(40.0)$ & $31(48.3)$ \\
No & $39(60.0)$ & $39(60.0)$ & $34(51.7)$ \\
$\begin{array}{l}\text { Group B } \\
\text { Yes }\end{array}$ & $27(41.7)$ & $24(36.7)$ & $24(36.7)$ \\
No & $38(58.3)$ & $41(63.3)$ & $41(63.3)$ \\
\hline$X=11.852 ; p$ & 0.011 & &
\end{tabular}

$X=11.852 ; p=0.011$

The subjects of the experimental groups were statistically more afraid of falling in the indoor environment comparing to the subjects of the control group, $p=0.023$ (Table 10). The subjects of Group A were statistically more afraid of falling
TABLE 7. The incidence of $>2$ falls in the current year

\begin{tabular}{cccc}
\hline Group & $\begin{array}{c}\text { First survey } \\
n(\%)\end{array}$ & $\begin{array}{c}\text { Second survey } \\
n(\%)\end{array}$ & $\begin{array}{c}\text { Third survey } \\
n(\%)\end{array}$ \\
\hline $\begin{array}{c}\text { Control } \\
\text { Yes }\end{array}$ & $0(0)$ & $0(0)$ & $0(0)$ \\
No & $130(100.0)$ & $130(100)$ & $130(100.0)$ \\
Group A & & & \\
Yes & $11(16.7)$ & $11(16.7)$ & $5(8.3)$ \\
No & $54(83.3)$ & $54(83.3)$ & $60(91.7)$ \\
Group B & & & \\
Yes & $11(16.7)$ & $11(16.7)$ & $11(16.7)$ \\
No & $54(83.3)$ & $54(83.3)$ & $54(83.3)$ \\
\hline$X=12.852 ; p=0.003$ & &
\end{tabular}

TABLE 8. Necessity of medical assistance after the fall

\begin{tabular}{cccc}
\hline Group & $\begin{array}{c}\text { First survey } \\
n(\%)\end{array}$ & $\begin{array}{c}\text { Second survey } \\
n(\%)\end{array}$ & $\begin{array}{c}\text { Third survey } \\
n(\%)\end{array}$ \\
\hline Control & & & \\
Yes & $7(5.0)$ & $13(10.0)$ & $13(10.0)$ \\
No & $123(95.0)$ & $117(90.0)$ & $117(90.0)$ \\
Group A & & & \\
Yes & $9(13.3)$ & $8(11.7)$ & $10(15.0)$ \\
No & $56(86.7)$ & $57(88.3)$ & $55(85.0)$ \\
Group B & & & \\
Yes & $10(15.0)$ & $10(15.0)$ & $9(13.3)$ \\
No & $55(85.0)$ & $55(85.0)$ & $56(86.7)$ \\
\hline X=8.852; $p=0.043$ & &
\end{tabular}

TABLE 9. Rate of fracture after the fall

\begin{tabular}{cccc}
\hline Group & $\begin{array}{c}\text { First survey } \\
n(\%)\end{array}$ & $\begin{array}{c}\text { Second survey } \\
n(\%)\end{array}$ & $\begin{array}{c}\text { Third survey } \\
n(\%)\end{array}$ \\
\hline Control & & & \\
Yes & $7(5.0)$ & $13(10.0)$ & $13(10.0)$ \\
No & $123(95.0)$ & $117(90.0)$ & $117(90.0)$ \\
Group A & & & \\
Yes & $7(10.0$ & $8(11.7)$ & $9(13.3)$ \\
No & $59(90.0)$ & $57(88.3)$ & $56(86.7)$ \\
Group B & & & \\
Yes & $8(11.7)$ & $7(10.0)$ & $5(8.3)$ \\
No & $57(88.3)$ & $59(90.0)$ & $60(91.7)$ \\
\hline X=6.715; $p=0.037$ & &
\end{tabular}

outdoors compared to the subjects of the control and Group B, $p=0.023$ (Table 11).

There were no statistically significant differences for the following facts: In avoiding going out (leaving home area) due to fear of falling in relation to the 
experimental groups, $p=0.689$, in the presence of somatic diseases which require regular medical

TABLE 10. The presence of anxiety due to possible fall in a closed space (bathtub, kitchen)

\begin{tabular}{lccc}
\hline Group & $\begin{array}{c}\text { The first } \\
\text { study } \\
n(\%)\end{array}$ & $\begin{array}{c}\text { The second } \\
\text { study } \\
n(\%)\end{array}$ & $\begin{array}{c}\text { The third } \\
\text { study } \\
n(\%)\end{array}$ \\
\hline $\begin{array}{c}\text { Control } \\
\text { Yes }\end{array}$ & $42(32.5)$ & $44(34.2)$ & $41(31.7)$ \\
No & $88(67.5)$ & $86(65.8)$ & $89(68.3)$ \\
$\begin{array}{c}\text { Group A } \\
\text { Yes }\end{array}$ & $36(55.0)$ & $35(53.3)$ & $35(53.3)$ \\
No & $29(45.0)$ & $30(46.7)$ & $30(46.7)$ \\
$\begin{array}{c}\text { Group B } \\
\text { Yes }\end{array}$ & $22(33.3)$ & $22(33.3)$ & $22(33.3)$ \\
No & $43(66.7)$ & $43(66.7)$ & $43(66.7)$ \\
\hline$X=4.528 ;$ & & &
\end{tabular}

$\mathrm{X}=4.528 ; p=0.023$

TABLE 11. The presence of anxiety due to possible fall in an open space (bus, stairs, street)

\begin{tabular}{lccc}
\hline Group & $\begin{array}{c}\text { The first } \\
\text { study } \\
n(\%)\end{array}$ & $\begin{array}{c}\text { The second } \\
\text { study } \\
n(\%)\end{array}$ & $\begin{array}{c}\text { The third } \\
\text { study } \\
n(\%)\end{array}$ \\
\hline $\begin{array}{l}\text { Control } \\
\text { Yes }\end{array}$ & $44(34.2)$ & $42(32.5)$ & $46(35.0)$ \\
No & $86(65.8)$ & $88(67.5)$ & $85(65.0)$ \\
$\begin{array}{l}\text { Group A } \\
\text { Yes }\end{array}$ & $41(63.3)$ & $39(60.0)$ & $39(60.0)$ \\
No & $24(36.7)$ & $26(40.0)$ & $26(40.0)$ \\
$\begin{array}{l}\text { Group B } \\
\text { Yes }\end{array}$ & $29(45.0)$ & $28(43.3)$ & $28(43.3)$ \\
No & $36(55.0)$ & $37(56.7)$ & $37(56.7)$ \\
\hline$X=6.258 ; p=0.023$ & &
\end{tabular}

$\mathrm{X}=6.258 ; p=0.023$ supervision in relation to the experimental groups, $p=0.298$, in the need for a home medical social care in the experimental groups $p=0.311$, in pathological conditions that can cause a fall in relation to the experimental groups, $p=0.147$, as well as in the use of medical therapy which potentially can cause a fall in regard to the experimental groups, $p=0.152$.

The average number of risk factors did not statistically differ significantly at the beginning, and the subjects of the control group had an average of 8.39, the Group A subjects 8.17 , and the group B subjects 8.80 . After the second study, the number of risk factors decreased mostly in the subjects of Group B. After the last survey, the number of risk factors mainly decreased in Group $\mathrm{A}$ (7.60), followed by Group B subjects (7.97) (Figure 1).

\section{DISCUSSION}

In this research, by applying descriptive statistics on the number and frequency of risk factors in control and experimental groups at the end of the study, it was found that the number of risk factors, compared to the first experiment, decreased in both experimental groups. Avdić and Pecar in their study of 77 subjects conducted in Sarajevo examined the balance, falls risk factors, and distribution of falls among people aged 65-90 years.

The study carried out in Sarajevo, which concerned the risk factor assessment in older adults, showed that $27.27 \%$ of people in the total sample $(n=77)$ experienced a fall in the past 6 months (17). The results of these studies agree with the results of our research which show in the total sample $(n=260) 27.1$ subjects experienced a fall once or 2 times a year.

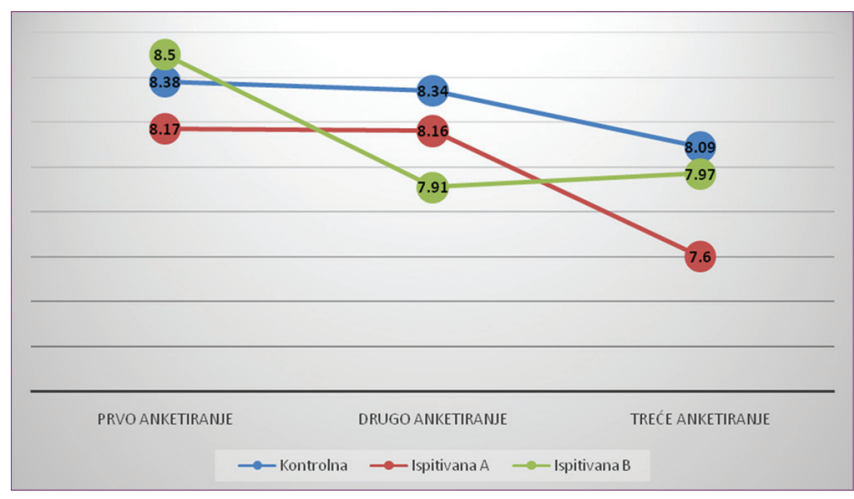

FIGURE 1. Relative index of the average number of risk factors. 
Boffin et al. studied the fall risk in their cross-sectional study conducted in Belgium on a sample of 715 older adults. The results of this study showed that $2.5 \%$ of the subjects had a fracture after a fall (18). The WHO states that falls lead up to $20-30 \%$ of slight to severe injuries, which are the cause of $10-15 \%$ of all doctor's visits (19).

Guthrie et al. studied the impact of the medication therapy in the elderly and its role in the emergence of fear of falling as well as the occurrence of limitations to daily living tasks due to fear of falling. The study included 441 subjects whose average lifespan was 80.7 years. Of the total number, $29.3 \%$ of subjects reported having limitations to daily living tasks due to fear of falling (20). Our study did not explicitly contain the question of whether there were restrictions on daily living tasks due to fear of falling, but we had a question as to whether the subjects avoided going out due to the fear of falling. It is quite sure that fear of leaving home is a limitation to everyday life activities because a person is not able to achieve adequate social interaction, get groceries, pay bills, etc. These data do not coincide with the results of our study in which we found that, of the total sample $(n=260), 5.76 \%$ avoided going out due to fear of falling at the beginning of the study, while at the end of the study that percentage reached to $7.69 \%$.

A large number of studies indicate the presence of fear of falling as one of the fall risk factors. Thus, in the Korean longitudinal study from 2010, concerning the elderly persons, the researchers analyzed the presence of fear of falling and limitations to daily life activities due to fear of falling. The researchers reported that $48.6 \%$ of subjects have a fear of falling, and $28.9 \%$ of subjects said that there is a limitation to daily living task due to fear of falling (21). In the study on 33 subjects which aimed at investigating the presence of fear of falling and the impact of fear on completing daily living tasks, Danish researcher Jellesmark et al. found that $58 \%$ of subjects had a high degree of fear (22).

The results of our study showed a slightly higher percentage of subjects who indicated that they generally have a fear of falling. Of the total number ( $n=260), 60.4 \%$ of the subjects reported the presence of fear of falling.
In a study conducted in the USA, Kaufman et al. and his associates state that the proportion of older adults using at least one medication per day ranges from $85 \%$ to $90 \%$ (23). The results of this study agree with the results of our study in which we received data referring to $83.8 \%$ of the patients who use at least one medication daily (of the total sample $[n=260])$.

\section{CONCLUSION}

We conclude that there is a significant decrease in the frequency and the average number of risk factors in the experimental groups, while in the control group, the number of risk factors remained the same.

By evaluating the FEMBAF questionnaire score in relation to the degree of fall risk among the observed groups, we realized that, at the beginning of the study, the highest level of fall risk was present in the Group A. At the end of the study, the degree of fall risk significantly decreased in the experimental Group A, and the final FEMBAF scores differed from the Group B and control group.

Analyzing the results obtained from the FEMBAF questionnaires which refer to the subjects' subjective complaints about fear, the presence of pain, difficult mobility, and weakness while performing tasks, we realized that the Groups A and B showed a significant reduction of subjective complaints. At the end of the study, the group that completed moderate intensity exercises with Theraband straps (Group A) showed statistically significant reduction of subjective complaints, both of fear and pain, of difficulties in mobility and lack of strength. In Group B, a substantial reduction in patient complaints was recorded concerning problems in movement and lack of strength, while in the control group, specific complaints even worsened. The study results indicate that the programmed therapeutic exercises in the elderly have much better effects in terms of reducing the falls risk compared to people older than 65 who are not engaged in any programmed therapeutic exercises.

\section{REFERENCES}

1. Marik PE. The geriatric ICU patient. In: Evidence-Based Critical Care. Switzerland: Springer International Publishing; 2015. p. 773-85. 
2. Deeg DJH, Litwin H, Wahl HW. The European journal of ageing and the debate on consequences of population ageing. Eur $\mathrm{J}$ Ageing 2014;11(1):1-3.

https://doi.org/10.1007/s10433-014-0309-9.

3. Avdić D. Pad u Trećoj Životnoj Dobi. Sarajevo: Oko; 2004. p. 40-3.

4. Barry E, Galvin R, Keogh C, Horgan F, Fahey T. Is the timed up and go test a useful predictor of risk of falls in community dwelling older adults: A systematic review and meta-analysis. BMC Geriatr 2014;14:14. https://doi.org/10.1186/1471-2318-14-14.

5. Hartholt KA, van Beeck EF, Polinder S, van der Velde N, van Lieshout EM, Panneman MJ, et al. Societal consequences of falls in the older population: Injuries, healthcare costs, and long-term reduced quality of life. J Trauma 2011;71(3):748-53.

https://doi.org/10.1097/TA.0b013e3181f6f5e5.

6. Hartholt KA, Polinder S, Van der Cammen TJ, Panneman MJ, Van der Velde N, Van Lieshout EM, et al. Costs of falls in an ageing population: A nationwide study from the Netherlands (2007-2009). Injury 2012;43(7):1199-203.

https://doi.org/10.1016/j.injury.2012.03.033.

7. Clegg A, Young J, lliffe S, Rikkert MO, Rockwood K. Frailty in elderly people. Lancet 2013;381(9868):752-62.

https://doi.org/10.1016/S0140-6736(12)62167-9.

8. National Center for Injury Prevention and Control. Web-Based Injury Statistics Query and Reporting System; 2013.

9. MilatAJ, Watson WL, Monger C, Barr M, Giffin M, Reid M, et al. Prevalence, circumstances and consequences of falls among community-dwelling older people: Results of the 2009 NSW falls prevention baseline survey. N S W Public Health Bull 2011;22(3-4):43-8. https://doi.org/10.1071/NB10065.

10. Martin KL, Blizzard L, Srikanth VK, Wood A, Thomson R, Sanders LM, et al. Cognitive function modifies the effect of physiological function on the risk of multiple falls--a population-based study. J Gerontol A Biol Sci Med Sci 2013;68(9):1091-7. https://doi.org/10.1093/gerona/glt010.

11. Tinetti ME, Speechley M. Prevention of falls among the elderly. N Engl J Med 1989;320(16):1055-9. https://doi.org/10.1056/NEJM198904203201606.

12. Rose DJ. Fallproof! a Comprehensive Balance and Mobility Training Program. Champaign: Human Kinetics; 2010.
13. American Physical Therapy Association. Guide to physical therapist practice. Second edition. American physical therapy association. Phys Ther 2001;81(1):9-746.

14. Sousa N, Mendes R, Abrantes C, Sampaio J, Oliveira J. Long-term effects of aerobic training versus combined aerobic and resistance training in modifying cardiovascular disease risk factors in healthy elderly men. Geriatr Gerontol Int 2013;13(4):928-35.

https://doi.org/10.1111/ggi.12033.

15. Selimanović M. Preventive corrective gymnastics for older adults, Aging Health Centre, Sarajevo, 2012;10-24

16. Faber MJ, Bosscher RJ, van Wieringen PC. Clinimetric properties of the performance-oriented mobility assessment. Phys Ther 2006;86(7):944-54.

17. Avdić D, Pecar D. Significance of specificity of tinetti B-POMA test and fall risk factor in third age of life. Bosn J Basic Med Sci 2006;6(1):50-7. https://doi.org/10.17305/bjbms.2006.3210.

18. Boffin N, Moreels S, Vanthomme K, Van Casteren V. Falls among older general practice patients: A 2-year nationwide surveillance study. Fam Pract 2014;31(3):281-9.

https://doi.org/10.1093/fampra/cmu002.

19. World Health Organization. Ageing, and Life Course Unit. WHO Global Report on Falls Prevention in Older Age. World Health Organization; 2008.

20. Guthrie DM, Fletcher PC, Berg K, Williams E, Boumans N, Hirdes JP, et al. The role of medications in predicting activity restriction due to a fear of falling. J Aging Health 2012;24(2):269-86.

https://doi.org/10.1177/0898264311422598.

21. Choi $\mathrm{K}, \mathrm{Ko} \mathrm{Y}$. Characteristics associated with fear of falling and activity restriction in South Korean older adults. J Aging Health 2015;27(6):1066-83. https://doi.org/10.1177/0898264315573519.

22. Jellesmark A, Herling SF, Egerod I, Beyer N. Fear of falling and changed functional ability following hip fracture among community-dwelling elderly people: An explanatory sequential mixed method study. Disabil Rehabil 2012;34(25):2124-31 https://doi.org/10.3109/09638288.2012.673685.

23. Kaufman DW, Kelly JP, Rosenberg L, Anderson TE, Mitchell AA. Recent patterns of medication use in the ambulatory adult population of the united states: The slone survey. JAMA 2002;287(3):337-44.

https://doi.org/10.1001/jama.287.3.337. 